\title{
More Infantile Hypertrophic Pyloric Stenosis?
}

\author{
Colonel J R Marshall, \\ L/RAMC \\ Consultant Paediatrician, Cambridge Military Hospital, Aldershot
}

SUMMARY: In 1978 there was a disproportionate increase in the number of cases of Infantile Hypertrophic Pyloric员 Stenosis (IHPS) admitted to the Cambridge Military Hospital Aldershot. This increase has not been sustained ino subsequent years, although the mean incidence for the period 1979/82 was slightly higher than the preceding years 1975/77. Analysis of the cases occurring in 1978 did not reveal any unusual factor relating to the increased incidence.

\section{Introduction}

Recent reports have suggested a rise in the incidence of Infantile Hypertrophic Pyloric Stenosis ${ }^{1,2,3}$. In 1978 the number of IHPS admitted to the Cambridge Military Hospital, Aldershot was 13, an incidence of 7 per 1000 for the annual delivery rate of approximately 1800 . All the cases were confirmed by surgery. In the years 1975 77 the mean annual incidence for the hospital was 2.8 per 1000 live births. The period 1979-82 had an annual mean incidence of 3 per 1000 . The incidence in the UK is given as 2-3 per 1000 live births ${ }^{4}$. The incidence of IHPS per 1000 live births in Central Scotland was shown to have increased from 2.2 in 1975 to 8.8 in $1979^{1}$. In the West Midlands region the increase was from 2.52 in 1975 to 3.64 in $1979^{2}$ and in South Glamorgan a mean incidence of 1.4 per 1000 live births before 1976 increased to 3.4 per 1000 from 1976 to $1979^{3}$.

\section{Patients and Methods}

The clinical notes of all cases of IHPS admitted to the Cambridge Military Hospital in 1979 were reviewed. A questionnaire was sent to the parents of these cases to determine if stress of any kind had occurred during the respective pregnancies. The degree of stress reported was categorised as described by Dodge ${ }^{8}$. The numbers of cases of IHPS admitted to the hospital in the period 1975-77 and 1979-82 were obtained from operating theatre records. As the numbers varied from 2 to $7 \mathrm{per}$ 1000 in each year a mean incidence was calculated for each period.

\section{Results}

Analysis of the cases of IHPS seen at the Cambridge Military Hospital in 1978 is summarised in Table 1 . The sex ratio was 11 males to 2 females, a M:F ratio of 5.5:1. No family history of IHPS was found in any of the cases. This was surprising because of the importance of genetic factors ${ }^{5}$. Primogeniture is often quoted to be significant, as many as $42 \%$ being first born ${ }^{6}$. Seven, or over $50 \%$ of our cases were first born. Five children $(39 \%)$ were breast fed for more than one week, most were breast fed until the onset of symptoms. Eight $(61 \%)$ were bottle
Table 1

Analysis of the Cases $(n=13)$

$\begin{array}{ll}\text { Sex Ratio M:F } & 5.5: 1 \\ \text { Family History } & 0 \\ \text { Primogeniture } & 50 \% \\ \text { Bottle Fed } & 61 \%\end{array}$

Mothers' Ages

Age at Presentation

Associated Abnomalities

Maternal Stress During Pregnancy

Range 19-29, mean 24 y Range 3-14, mean 5.7 wees $25 \%$

$30 \%$

fed from birth. Mothers' ages ranged from 19 to 29 ye with an average of 24 . The majority of the cases wereco social class III (based on father's rank) with only tipocr social class $\mathrm{V}$. The age range at presentation was 3-40 weeks with a mean of 5.7 weeks. Two babies we diagnosed only on second admission. One of these, who was first admitted at 9 weeks with doubtful symptoms, had a normal barium swallow. He was readmitted at $12 \%$ weeks vomiting "coffee grounds" and the pyloric tumour was then palpable. Two infants were prematureo with gestational ages of 34 and 35 weeks and one was small for gestational age. Both had had hyperbilirubinaemia and one required exchange: transfusion. The 34 week premature baby had a patent ductus and needed a barium swallow to distinguish the diagnosis of pyloric stenosis from incipient cardiace failure as a cause of his vomiting.

Post-operative courses of the preterm infants were uneventful. Two babies had inguinal herniae ${ }^{7}$ and $_{-}^{?}$ subsequently had further surgery before one year of age 3 . One baby had a urinary tract infection but radiologicalo investigation was normal? ${ }^{\text {? }}$ Review of the pregnancies? revealed that four mothers had significant stress aso defined by Dodge in his paper relating stress factors? during pregnancy to IHPS ${ }^{8}$. One mother had alreadyo had a handicapped child and her husband was seriously ill during her pregnancy and required a nephrectomy. Other stresses included a previous cot death and two orn three episodes of premature labour, absence of then husband on emergency duty abroad at the time of 
delivery, hyperemesis to term with poor weight gain, ingestion of the drugs Avomine, Debendox or Largactil for hyperemesis with anxiety about stillbirth, and conception with a coil in situ and anxiety about intrauterine death after the coil had been removed. Thus $30 \%$ of the families reported significant stress which compares with Dodge's findings of severe stress in 33\% of cases ${ }^{8}$.

\section{Discussion}

The mean incidence of IHPS at the Cambridge Military Hospital in the years $1979-82$ of 3 per 1000 was not significantly different from the period $1975-77$ with a mean of 2.8 per 1000 . Analysis of the cases of IHPS occurring in 1978 at the hospital did not reveal any unusual factor to explain the increased incidence ( 7 per 1000 ) of IHPS for that year though significant maternal stress was noted during a third of the pregnancies in this small series.

\section{REFERENCES}

1 KERR. A M. Unprecedented rise in incidence of infantile hypertrophic pyloric stenosis. Br Med J 1980; 281: 714-715.

2 KNox. E.G. Armstrong E And Haynes R. Changing incidence of infantile hypertrophic pyloric stenosis. Arch Dis. Child 1983; 58: 582.

3 Webs. A R, Lair, J and Dodge $\mathbf{J}$ A. Infantile hypertrophic pyloric stenosis in South Glamorgan 1970-9. Arch Dis Child 1983; 58: 586.

4 Forcar, J O AND ARNEILl, G C. Textbook of Paediatrics. 2nd Ed. 1978 P 398 Churchill and Livingstone.

5 Carter. C O AND Evans, K A. Inheritance of congenital pyloric stenosis. J Med Genet 1969: 6: 233.

6 DODGE. J A. Infantile hypertrophic pyloric stenosis in Belfast, 1957-69 Arch Dis Child 1975; 50: 171.

7 ATWELL. J D AND LEVICK. P. Hypertrophic pyloric stenosis and the urinary tract. Arch Dis Child 1980; 55: 732.

8 Dodge. J A. Psychosomatic aspects of infantile pyloric stenosis J Psychosom Res 1972, 16: 1-5.

\section{MEDICAL CORPS INTERNATIONAL}

This English language journal whose first issue is due out early next year will be edited by Rear Admiral KarlWilhelm Wedel who is also editor of Wehrmedizin und Wehrpharmazie (Military Medicine and Pharmacy).

Our own Surgeon General and Director General of Army Medical Services will be a member of the International Editorial Advisory Board.

No doubt from time to time authors from this country will wish to submit articles for publication in Medical Corps International. 